\title{
Urologists Are No Longer the Primary Surgeons for Several Urologic Operations: A National Survey Among the Turkish Urologists
}

\author{
(D) Serdar Madendere1, (D) Müslim Doğan Değer2, (D) Engin Denizhan Demirkıran3, (D) Hüseyin Alperen Yıldız \\ 1 Gümüşhane State Hospital, Clinic of Urology, Gümüşhane, Turkiye \\ 2Edirne Sultan $1^{\text {st }}$ Murat State Hospital, Clinic of Urology, Edirne, Turkiye \\ ${ }^{3}$ Şırnak State Hospital, Clinic of Urology, Şırnak, Turkiye \\ ${ }^{4}$ Malazgirt State Hospital, Clinic of Urology, Muş, Turkiye
}

\section{What's known on the subject? and What does the study add?}

To best of our knowledge, this is the first study which investigates the performance percentages of the surgeries that could be performed both by the urologists and other surgeons. This study shows that the urologists are no longer the main surgeons for some urological surgeries, and many urologists avoid performing the major urologic surgeries. However, urologists mostly agree that they should perform these surgeries. The study was conducted to increase the awareness among urologists.

\section{Abstract}

Objective: To investigate the role, interest, and competence of the Turkish urologists for urologic surgeries which are also performed by the other surgeons.

Materials and Methods: We conducted a 22-item online survey and invited urologists by e-mail. Questions were asked to evaluate the attitudes, performances, and capabilities of the urologists in surgeries which could be performed by the other surgeons.

Results: A total of 305 responses were evaluated. The female incontinence surgery, pediatric urologic surgery, and adrenal surgery are mostly performed by the urologists in their hospitals. Turkish urologists mostly do not perform the following surgeries and interventions themselves and refer patients to the other surgeons for a percutaneous nephrostomy (47.2\%), urinary diversions using the intestinal segments (44.9\%), kidney transplantation (11.8\%), and the transgender surgeries (7.2\%). Almost half of the urologists do not perform adrenal surgeries (50.2\%). Most urologists agree that they should be the main surgeons for all these surgeries.

Conclusion: Urologists are no longer the main surgeons for some surgeries which are included on the urologic curriculum. Many urologists avoid performing the major urologic surgeries. Urology educators should familiarize the new urologists with all the urologic surgeries.

Keywords: Urologic surgical procedures, transgender surgery, kidney transplantation, urinary diversion, adrenal surgery, female urology

\section{Introduction}

Many urologists have focused on the robotic and laparoscopic procedures, as a result of recent advances in minimally invasive surgery (1). These fields are promising for the development of urology in the future (2). However, urologists may no longer be the main surgeons for the certain operations, because of the involvement of the other departments. For example, in kidney transplantation, urologists were the main surgeons in the
United States in the past; however, many kidney transplants are performed by the general surgeons nowadays (3).

Percutaneous nephrostomy and renal access before a percutaneous nephrolithotomy (PCNL) are performed by the interventional radiologists in some countries (4). While the transgender surgery requires urology involvement in many of the aspects, this field is mainly dominated by the plastic surgeons (5). Adrenal surgeries, pediatric urologic surgeries, and 
female incontinence surgeries are also being performed both by the urologists and other surgeons. As a result, there is a risk that the surgical diversity of the urologists may decrease, and the residents may have less surgical exposure in these fields during the training. This could be defined as a loss for urology specialization economically and scientifically.

While involvement of the other departments in urology surgeries are observed, we hypothesized that the Turkish urologists are no longer the primary surgeons in some surgeries that they used to perform, and this may cause to a loss of interest and competence for the urology residents in the future. We conducted a survey to show the current situation, and to reveal the possible reasons for it. With this study, we would like to emphasize the importance of maintaining the surgical range in the urology department.

\section{Materials and Methods}

The study is based on the online survey that consisted of 22 questions with a multiple choice or yes/no options. The survey was created based on the checklist for reporting the results of internet E-surveys (CHERRIES) (6). Firstly, these questions inquired about the baseline characteristics of the responders. In the second part, there are questions about whether the urologists perform the listed surgeries in their hospitals. Common surgeries that could be performed by both the urologists and other surgeons like gynecologists, plastic surgeons, pediatric surgeons, general surgeons, and interventional radiologists were investigated with the questionnaire. The third part involves the perspectives of the urologists about whether the urologists or other surgeons should perform these surgeries. In the last part, self-confidence of the respondents in relation to the listed surgeries was evaluated.

After testing for feasibility with the ten responders, a total of 2305 actively working certified urologists and urology residents in the last year of the training were invited to the study by E-mail. After four weeks, reminder mails were also sent. Informed consent was not required because the study is not based on the patient groups. The survey was accessible between June and October 2020 through the web program Google Forms (Alphabet Co., Mountain View, CA). The Local Ethics Committee approved this study (Zonguldak Bülent Ecevit University 2020/10-5, date: 13.05.2020).

\section{Statistical Analysis}

Descriptive statistics were used to analyze the practice patterns and demographics. The respondents were classified according to the academic title, hospital type, and experience in urology stream. For each surgery, we separately determined whether it was performed in the hospital of responders. The numbers and percentages of the urologists who perform these surgeries in their hospitals were assessed. The proportions of all the urologists who think that urologists should perform these surgeries were calculated. Frequencies were compared by using the chi-square test. A $p$-value $<0.05$ was considered statistically significant. Statistical analyses were performed by using IBM Statistical Package for Social Sciences, version 21.0, software (IBM SPSS Corp., Armonk, NY, USA).

\section{Results}

A total of 351 out of 2305 urologists participated in this study. The response rate was $15.2 \%$. Among the questionnaires, a total of 46 incomplete questionnaires were excluded from the study, and 305 responses were evaluated. The median age of the responders was 36 years (27-66). The responders were employed in the urology practices for a median of ten (4-39) years. The demographics and other practice patterns are shown in Table 1. Urologists had high interest in the renal transplantation (97.4\%), but mostly general surgeons perform renal transplantation (88.2\%).

Most urologists stated that the female incontinence surgery, pediatric urologic surgery, and adrenal surgery are mostly performed by the urologists in their hospitals. Urologists remain in the minority for performing the other listed surgeries. The urologists, employed in the hospitals where these surgeries are performed by the urologists, mostly think that the urologists should perform these surgeries. In total, most urologists agree that all these surgeries should be performed by the urologists (Table 2, Figure 1).

\begin{tabular}{|c|c|c|}
\hline \multirow{5}{*}{$\begin{array}{l}\text { Experience in } \\
\text { practice in years, } \\
n(\%)\end{array}$} & $0-5$ & $63(20.7)$ \\
\hline & $5-10$ & $110(36.1)$ \\
\hline & $10-15$ & $48(15.7)$ \\
\hline & $15-20$ & $32(10.5)$ \\
\hline & 20 and more & $52(17)$ \\
\hline \multirow{5}{*}{$\begin{array}{l}\text { Age range in } \\
\text { years, } \mathrm{n}(\%)\end{array}$} & $25-34$ & $144(47.2 \%)$ \\
\hline & $35-44$ & $96(31.5)$ \\
\hline & $45-54$ & $42(13.7 \%)$ \\
\hline & $55-64$ & $20(6.6 \%)$ \\
\hline & 65 and more & $3(1 \%)$ \\
\hline \multirow{3}{*}{ Title, n (\%) } & Residents & $76(24.9 \%)$ \\
\hline & Specialists & $184(60.3 \%)$ \\
\hline & Academicians & $45(14.8 \%)$ \\
\hline \multirow{4}{*}{$\begin{array}{l}\text { Hospital type, n } \\
(\%)\end{array}$} & University hospital & $78(25.6 \%)$ \\
\hline & $\begin{array}{l}\text { Government based research } \\
\text { hospital }\end{array}$ & $70(22.9 \%)$ \\
\hline & State hospital & $106(34.8 \%)$ \\
\hline & Private hospital & $51(16.7 \%)$ \\
\hline
\end{tabular}


Table 3, presents the percentages of the urologists who feel competent performing different surgery types and think urologists should perform these surgeries according to an academic title.

Except the percutaneous nephrostomy and pediatric urologic surgery, all the surgeries are mostly performed in the tertiary care hospitals.

\section{Discussion}

To the best of our knowledge, this is the first national research which illustrates the role and attitude of the urologists about surgical procedures that are also performed by the other surgeons. Our results demonstrate that the urologists are no longer the primary surgeons for some surgeries related to their field. On the other hand, most of them think that they should perform these surgeries.

Morrison et al. (5) showed that the urology residents had less theoretical and practical exposure to a transgender surgery than the plastic surgery residents. Urologists are surgeons for the genitourinary tract and urologic care which is essential for transgender patients having issues with a voiding dysfunction, fistulas, and penile prosthesis revision (7). Therefore, they should be at the center of transgender multidisciplinary teams. Training during the residency is essential to reach this awareness. On this point, the attitude of the training program director is significant. Comprehensive transgender practice during the residency may ensure the dominance of the urologists in this field in the future.

There is a similar issue between the urologists and general surgeons. This study shows that the kidney transplantation and even donor nephrectomy are performed mostly by the general surgeons despite the high interest of urologists. Similarly, in the United States, urologists are no longer the primary surgeons in this field (3). Adrenalectomy is another operation which could be performed by both the general surgeons and urologists. Fuletra et al. (8) highlighted that only 10\% of the 3358 adrenalectomies were performed by the urologists in the United States. Only half of Turkish urologists perform adrenalectomy in

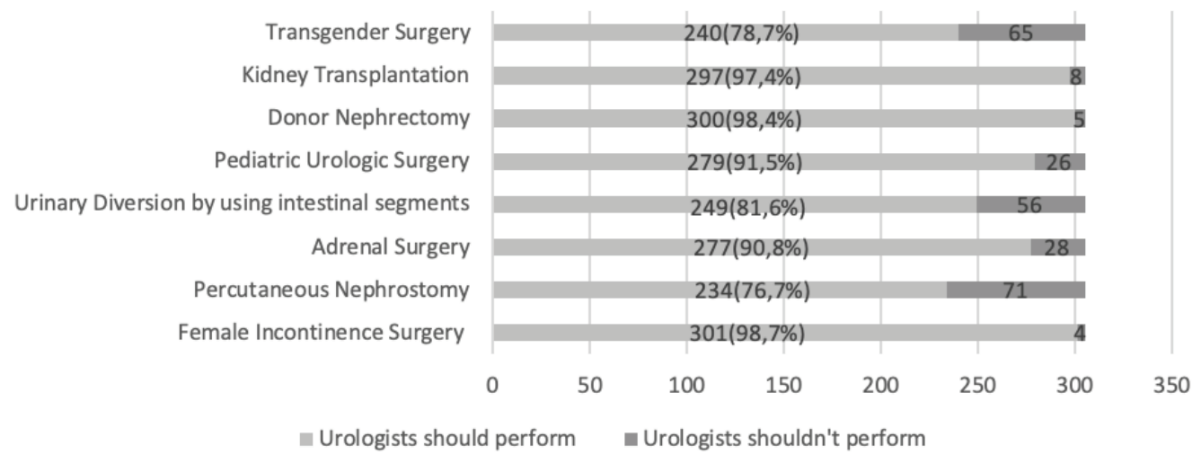

Figure 1. Total numbers of urologists who believe that urologists should perform these surgeries

Table 2. Percentages of urologists performing these surgeries in their hospital, and who think that urologists should perform these surgeries

\begin{tabular}{|c|c|c|c|c|c|}
\hline \multirow[t]{2}{*}{ Surgery type } & \multicolumn{2}{|c|}{ Performing urologists ${ }^{a}$} & \multicolumn{2}{|c|}{$\begin{array}{l}\text { Percentages of performing urologists } \\
\text { who think urologists should perform } \\
\text { the operation }{ }^{b}\end{array}$} & \multirow[t]{2}{*}{ p-value ${ }^{c}$} \\
\hline & $\mathbf{n}$ & $\%$ & $\mathbf{n}$ & $\%$ & \\
\hline Female incontinence surgery & 256 & $83.9 \%$ & 253 & $98.8 \%$ & 0.624 \\
\hline Percutaneous nephrostomy & 144 & $47.2 \%$ & 125 & $86.8 \%$ & $<0.01$ \\
\hline Adrenal surgery & 153 & $50.2 \%$ & 146 & $95.4 \%$ & $<0.01$ \\
\hline Urinary diversion $^{\mathrm{d}}$ & 137 & $44.9 \%$ & 129 & $94.2 \%$ & $<0.01$ \\
\hline Pediatric urologic surgery & 242 & $79.3 \%$ & 229 & $94.6 \%$ & $<0.01$ \\
\hline Donor nephrectomy & 43 & $14.1 \%$ & 42 & $97.7 \%$ & 0.700 \\
\hline Kidney transplantation & 36 & $11.8 \%$ & 36 & $100 \%$ & 0.290 \\
\hline Transgender surgery & 22 & $7.2 \%$ & 20 & $90.9 \%$ & 0.146 \\
\hline
\end{tabular}




\begin{tabular}{|c|c|c|c|c|c|}
\hline \multirow{2}{*}{ Surgery type } & \multirow{2}{*}{ Title } & \multicolumn{2}{|c|}{ Capability for surgeries $^{a}$} & \multicolumn{2}{|c|}{ Urologists should perform these surgeries ${ }^{b}$} \\
\hline & & $\mathbf{n}$ & $\%$ & n & $\%$ \\
\hline \multirow{4}{*}{$\begin{array}{l}\text { Female incontinence } \\
\text { surgery }\end{array}$} & Residents & 50 & $65.8 \%$ & 74 & $97.4 \%$ \\
\hline & Specialists & 121 & $65.8 \%$ & 183 & $99.5 \%$ \\
\hline & Academics & 40 & $88.9 \%$ & 44 & $97.8 \%$ \\
\hline & Overall & 211 & $69.2 \%$ & 301 & $98.7 \%$ \\
\hline \multirow{4}{*}{ Percutaneous nephrostomy } & Residents & 55 & $72.4 \%$ & 60 & $78.9 \%$ \\
\hline & Specialists & 130 & $70.7 \%$ & 139 & $75.5 \%$ \\
\hline & Academics & 37 & $82.2 \%$ & 35 & $77.8 \%$ \\
\hline & Overall & 222 & $72.8 \%$ & 234 & $76.7 \%$ \\
\hline \multirow{4}{*}{ Adrenal surgery } & Residents & 29 & $38.2 \%$ & 66 & $86.8 \%$ \\
\hline & Specialists & 49 & $26.6 \%$ & 167 & $90.8 \%$ \\
\hline & Academics & 32 & $71.1 \%$ & 44 & $97.8 \%$ \\
\hline & Overall & 110 & $36.1 \%$ & 277 & $90.8 \%$ \\
\hline \multirow{4}{*}{ Urinary diversion $^{\mathrm{c}}$} & Residents & 42 & $55.3 \%$ & 56 & $73.7 \%$ \\
\hline & Specialists & 74 & $40.2 \%$ & 153 & $83.2 \%$ \\
\hline & Academics & 39 & $86.7 \%$ & 40 & $88.9 \%$ \\
\hline & Overall & 155 & $50.8 \%$ & 249 & $81.6 \%$ \\
\hline \multirow{4}{*}{ Pediatric urologic surgery } & Residents & 34 & $44.7 \%$ & 67 & $88.2 \%$ \\
\hline & Specialists & 115 & $62.5 \%$ & 170 & $92.4 \%$ \\
\hline & Academics & 37 & $82.2 \%$ & 42 & $93.3 \%$ \\
\hline & Overall & 186 & $61.0 \%$ & 279 & $91.5 \%$ \\
\hline
\end{tabular}

their hospitals. Urologists should be well trained for a surgery of the retroperitoneum and should maintain adrenalectomy and donor nephrectomy in their repertoire. The urologist's experience will always be inextricably linked to the past, nature, and complexities of the kidney transplantation (9).

According to the Accreditation Council for Graduate Medical Education data, urology residents have limited exposure to the urinary diversions (10). Another study showing the practice patterns of certifying the American urologists found, only $37 \%$ of them performed any urinary diversions (11). There is a similar percentage among the responders of this study. The possible explanation for this situation is again insufficient exposure to the urinary diversions during their residency. Another possible reason may be the necessity of using the intestinal segments for some urinary diversions. Urologists should be competent to prepare the intestinal segments for urinary diversions by themselves instead of referring to the general surgeons. Urologists should be competent enough to perform the urinary diversions that may be required for emergency cases.
In the United States, gynecologists perform most sling procedures, and in Canada urologists perform 43\% of these surgeries. The same study showed that the urologists diagnose fewer patients with a pelvic organ prolapse (POP) (12). On the other hand, there are similar outcomes for POP surgery performed by the urologists or gynecologists (13). Among our responders, there is higher performance and interest in a female incontinence surgery and pediatric urologic surgery compared to the other surgeries. Possible reasons are that these surgeries have shorter learning curves and urologists have more exposure during the residency.

Most urologists feel competent about a percutaneous nephrostomy, but performance rates are lower. Urologists tend to leave this field to interventional radiologists. In some countries, there is a trend that the most access for PCNL is performed by an interventional radiologist (14). But it is a fact that an interventional radiology department is not always available in the small cities and hospitals. Percutaneous nephrostomy replacement could be lifesaving in some cases. Therefore, urologists should be able to perform percutaneous renal access on their own. Urologists may successfully perform 
the renal access with low complication rates (15). Residents should practice percutaneous nephrostomy during their training instead of referring the patients to the interventional radiologists continuously (16).

\section{Study Limitations}

This study should be evaluated with its limitations. There could be recall and response bias due to the nature of the survey. The responders may be only those interested or not interested in these surgeries. The results cannot be expanded due to its' demographic bias. Surgery types were assessed under general headings and not investigated in detail. Another limitation is that the surgeon preferences are given as percentages rather than the actual number of the surgeries.

\section{Conclusion}

In Turkey, urologists are no longer the primary surgeons for some surgeries they used to perform. Many urologists avoid performing the major urologic surgeries. As vital as it is for urologists to be involved in emerging technology and surgery procedures, it is also critical that they continue to conduct surgeries that are part of the urology curriculum. Urology educators should familiarize the new urologists with these surgeries and how to manage their complications. We hope that the urology will continue to be the focus of newly graduated doctors due to a vast range of surgical procedures available.

\section{Ethics}

Ethics Committee Approval: The Local Ethics Committee approved this study (Zonguldak Bülent Ecevit University 2020/10-5, date: 13.05.2020).

Informed Consent: Informed consent was not required because the study is not based on the patient groups.

Peer-review: Externally peer-reviewed.

\section{Authorship Contributions}

Surgical and Medical Practices: S.M., M.D.D., E.D.D., H.A.Y., Concept: S.M., M.D.D., E.D.D., H.A.Y., Design: S.M., M.D.D., E.D.D., H.A.Y., Data Collection or Processing: S.M., M.D.D., E.D.D., H.A.Y., Analysis or Interpretation: S.M., M.D.D., E.D.D., H.A.Y., Literature Search: S.M., M.D.D., E.D.D., H.A.Y., Writing: S.M., M.D.D., E.D.D., H.A.Y.

Conflict of Interest: No conflict of interest was declared by the authors.
Financial Disclosure: The authors declare that they have no relevant financial.

\section{References}

1. Eswara JR. Minimally Invasive Tecniques in Urology. 2018.

2. Özdener F, Sursal A, Narter F. Current Status of Urological Surgery Clinical Trials in the Middle East and Its Analysis in Comparison to Global. J Urol Surg 2019;6:266-272.

3. Sackett $D D$, Singh $P$, Lallas $C D$. Urological involvement in renal transplantation. Int J Urol 2011;18:185-193.

4. El-Assmy AM, Shokeir AA, Mohsen T, El-Tabey N, El-Nahas AR, Shoma AM, Eraky I, El-Kenawy MR, El-Kappany HA. Renal access by urologist or radiologist for percutaneous nephrolithotomy--is it still an issue? J Urol 2007;178:916-920.

5. Morrison SD, Dy GW, Chong HJ, Holt SK, Vedder NB, Sorensen MD, Joyner BD, Friedrich JB. Transgender-Related Education in Plastic Surgery and Urology Residency Programs. J Grad Med Educ 2017;9:178-183.

6. Eysenbach G. Improving the quality of Web surveys: the Checklist for Reporting Results of Internet E-Surveys (CHERRIES). J Med Internet Res 2004;6:e34.

7. Dy GW, Osbun NC, Morrison SD, Grant DW, Merguerian PA; Transgender Education Study Group. Exposure to and Attitudes Regarding Transgender Education Among Urology Residents. J Sex Med 2016;13:1466-1472.

8. Fuletra JG, Schilling AL, Canter D, Hollenbeak CS, Raman JD. Adrenalectomy: should urologists not be doing more? Int Urol Nephrol 2020;52:197-204.

9. Branchereau J. Rede ning the urologist's role in kidney transplantation. 2020;(0123456789):3-4. doi: 10.1007/s00345-020-03520-5

10. Chang SS, Smith JA Jr, Herrell SD, Cookson MS. Assessing urinary diversion experience in urologic residency programs-are we adequately training the next generation? J Urol 2006;176:691-693.

11. Silberstein JL, Poon SA, Maschino AC, Lowrance WT, Garg T, Herr HW, Donat SM, Dalbagni G, Bochner BH, Sandhu JS. Urinary diversion practice patterns among certifying American urologists. J Urol 2013;189:1042-1047.

12. James MB, Theofanides MC, Sui W, Onyeji I, Badalato GM, Chung DE. Sling Procedures for the Treatment of Stress Urinary Incontinence: Comparison of National Practice Patterns between Urologists and Gynecologists. J Urol 2017;198:1386-1391.

13. Citgez S, Oncul M, Demirdag C, Ercili B, Cetinel B. Does being performed by urologist or gynecologist affect the outcomes of women who have had sacrocolpopexy? Eur J Obstet Gynecol Reprod Biol 2019;237:64-67.

14. Armitage JN, Withington J, Fowler S, Finch WJG, Burgess NA, Irving SO, Glass J, Wiseman OJ; BAUS section of Endourology. Percutaneous nephrolithotomy access by urologist or interventional radiologist: practice and outcomes in the UK. BJU Int 2017;119:913-918.

15. İşoğlu CS, İlbey YÖ. Our Multiple Single-step Access Results in Percutaneous Nephrolithotomy. J Urol Surg 2019;6:7-10.

16. Değer MD, Yıldız HA, Demirkıran ED, Madendere S. Current status of urological training and differences between institutions, Actas Urológicas Españolas 2022. https://doi.org/10.1016/j.acuroe.2022.01.003 